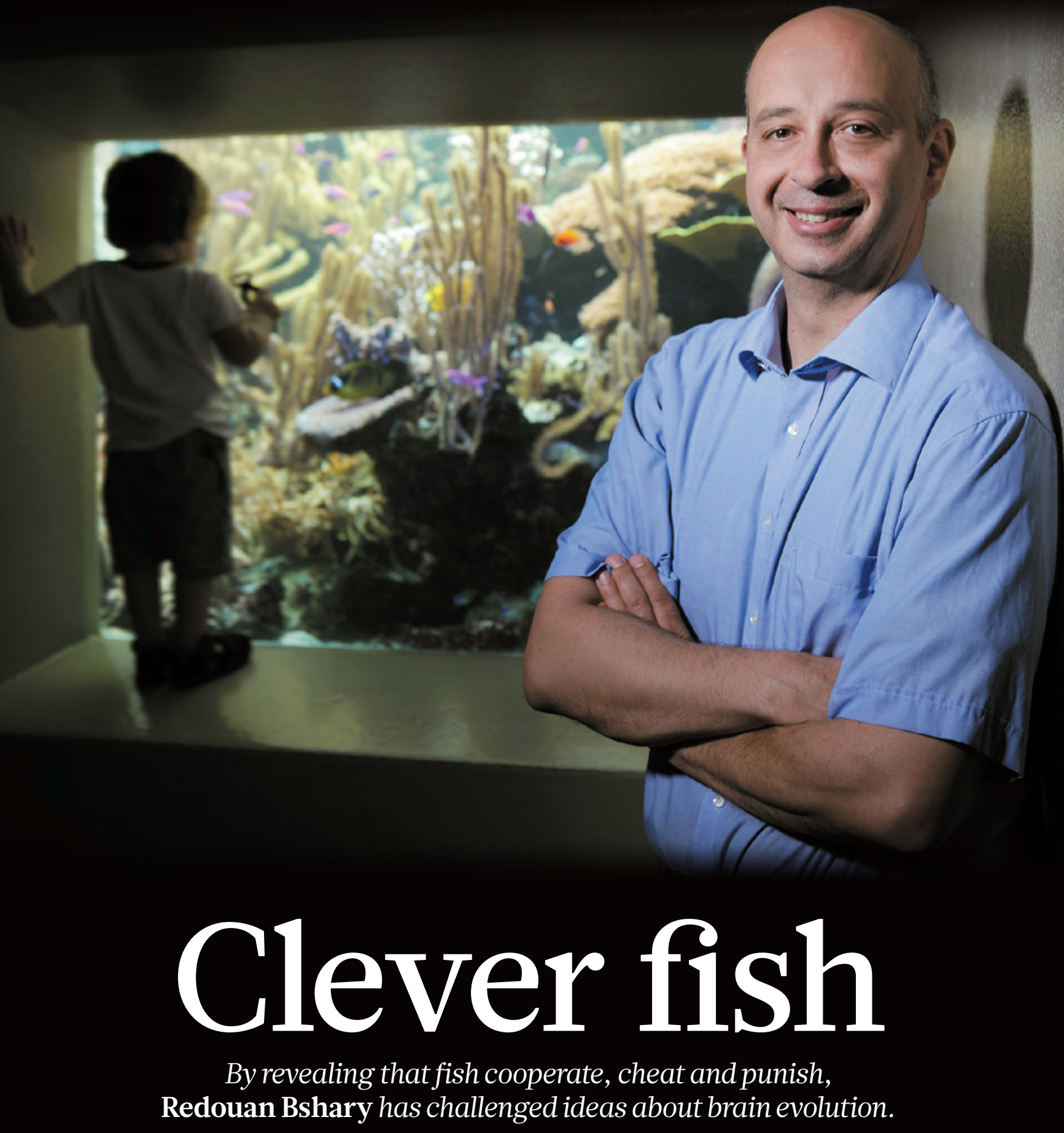

BY ALISON ABBOTT

$\mathrm{R}$ edouan Bshary well remembers the moment he realized that fish were smarter than they are given credit for. It was 1998, and Bshary was a young behavioural ecologist with a dream project: snorkelling in Egypt's Red Sea to observe the behaviour of coral-reef fish. That day, he was watching a grumpy-looking grouper fish as it approached a giant moray eel.

As two of the region's top predators, groupers and morays might be expected to compete for their food and even avoid each other - but Bshary saw them team up to hunt. First, the grouper signalled to the eel with its head, and then the two swam side by side, with the eel dipping into crevices, flushing out fish beyond the grouper's reach and getting a chance to feed alongside. Bshary was astonished by the unexpected
Redouan Bshary studies social behaviour of coral-reef fish. 
cooperation; if he hadn't had a snorkel in his mouth, he would have gasped.

This underwater observation was the first in a series of surprising discoveries that Bshary has gone on to make about the social behaviour of fish. Not only can they signal to each other and cooperate across species, but they can also cheat, deceive, console or punish one another even show concern about their personal reputations. "I have always had a lot of respect for fish," says Bshary. "But one after the other, these behaviours took me by surprise."

His investigations have led him to take a crash course in scuba diving, go beach camping in Egypt and build fake coral reefs in Australia. The work has also destroyed the stereotypical idea that fish are dumb creatures, capable of only the simplest behaviours - and it has presented a challenge to behavioural ecologists in a different field. Scientists who study primates have claimed that human-like behaviours such as cooperation are the sole privilege of animals such as monkeys and apes, and that they helped to drive the evolution of primates' large brains. Bshary - quiet, but afraid of neither adventure nor of contesting others' ideas - has given those scientists reason to think again.

"Redouan has thrown down the gauntlet to us primatologists," says Carel van Schaik, an expert in orang-utan culture at the University of Zurich in Switzerland. "He has made us realize that some of the explanations of primate intelligence that we have cherished don't hold water anymore."

\section{Stream fishing}

Bshary says that he was "pre-imprinted to like fish". As a child in Starnberg, Germany, he played constantly in the stream at the edge of the family garden, building dams and pools and trapping fish. Passionate about animal behaviour, he studied evolutionary ecology at the University of Munich, and then did a PhD at the Max Planck Institute for Behavioural Physiology in Starnberg. But for his field work, he journeyed to the Côte d'Ivoire, where he followed tree-living monkeys and discovered that different species collaborate to reduce predator risk.

His $\mathrm{PhD}$ supervisor, Ronald Noë, thought it would be "near impossible" to stalk monkeys that leap from tree-top to tree-top, but Bshary seemed to have a flair for it. On occasion, he even camouflaged himself under a leopard skin to imitate one of their predators. And he became fascinated by one question: what makes animals cooperate when standard natural selection would predict selfish behaviour to be the norm?

Noë, a primate behavioural ecologist now at the Hubert Curien Multidisciplinary Institute in Strasbourg, France, had come up with a biological market-based theory of cooperation. It proposed that animals cooperate to trade a specific commodity - such as food - for a service that would promote their survival, such as protection from a predator ${ }^{1}$. "An attractive theory - but, there were no strong data to support it," says Bshary.

He looked around for a system where market forces might be operating. And he found one when Hans Fricke, a fish ecologist working at the Max Planck institute, told him the strange tale of barrier-reef fish that operate a remarkable system of cooperation. 'Cleaner' fish, such as the brightly striped wrasse, will nibble parasites off the skin of 'client' fish in small coral territories known as cleaning stations. Bshary realized that this provided a perfect situation in which to test the market theory because client fish seemed to be trading food - in the form of parasites - for a skin-cleaning service. He decided to follow his hunch and study the coral-reef fish.

There was one small problem: Bshary had never been scuba diving. He took his first lessons during a snowy winter in Lake Starnberg, then set off for the Red Sea, setting up camp in Ras Mohammed National Park in Egypt. Together with a few students, Bshary spent two full months a year camped on a scorching beach, sleeping under the stars, eating a diet of fruit and vegetables and doing four exhausting, 75-minute dives a day. "In the mornings he would wake up and immediately put on his wetsuit and jump straight into the sea," recalls former student Erica van de Waal, now a research fellow at the University of Zurich. Armed with a plastic underwater writing slate, a pencil and a stopwatch, he shadowed client fish, observing their interactions with the wrasse cleaner fish - and soon collected evidence of a well-functioning market. "For me this system was a gold mine," Bshary says, and he mined a lot of gold.

He discovered, for example, that fish did not just trade parasites for skin cleaning; the cleaner fish also cheated on the deal. Rather than eating parasites, they actually preferred the nutritious protective mucus that covers fish skin, and were constantly tempted to take a quick, illicit bite of it. Bshary could count how often this happened - and therefore whether the clients were getting a good or a bad cleaning service - because the clients gave a jolt when they were bitten.

The market theory predicted that if there were lots of clients around, the cleaners would enjoy a seller's market and would risk taking more bites of mucus. This is just like a mechanic getting away with shoddy car services when there are no competing businesses in town. Bshary found this to be true, and he also found that the buyers could protest. Because some client fish roam large territories, they could choose to boycott any cleaning stations that deliver a bad service - just as someone who received a poor car service might travel farther to find a better garage ${ }^{2}$.

While racking up evidence for the market theory, Bshary also observed a range of other social behaviours that had never been seen before in fish. He saw that unsatisfied clients sometimes punish cheating cleaners by chasing them around, and that this punishment makes these fish less likely to cheat ${ }^{3}$. He saw cleaners ingratiating themselves with certain clients: they gave preference to visiting fish such as groupers, rather than the smaller, local fish that did not have the option of going elsewhere. He found that the cleaners cheated less when they were being watched by other potential clients - a sign that they were buffing their reputations ${ }^{4}$. And he saw reconciliation: if cleaners behaved badly, they then massaged the backs of offended clients with their pelvic fins ${ }^{5}$.

It was all adding up to a catalogue of behaviours worthy of Niccolò Machiavelli's The Prince - but it was based on observation alone. Bshary needed to move to an experimental set-up where he could test how the fish behaved. And so in 2003, he began experiments at Lizard Island Research Station on Australia's Great Barrier Reef. He was employed, however, on the other side of the world: first at the University of Liverpool, UK, and now at the University of Neuchâtel, Switzerland. "It was not difficult to sign up to a lifetime of fieldwork at warm coral beach locations," he admits.

Over the next few years Bshary would capture fish in the wild reefs, house them in tanks for the duration of his experiments, then release them. He simulated the choice that cleaners make between parasites and mucus by building moveable plastic plates smeared with prawn, which the fish love, and fish flakes, which they enjoy less. In this set-up, the plates may be snatched away if the cleaners go for the prawns - just like a client fish may swim away if its mucus gets bitten too often. So the cleaners learned to cooperate and eat fish flakes instead.

Such experiments take patience: some fish take a month just to adjust to the tanks. But in this way, Bshary proved that all the behaviours he had observed in the wild could be repeated under experimental conditions. And he discovered even more bizarre facts about the social lives of fish. In one experiment, he showed that when cleaners work in male and female pairs, as frequently happens in the wild, they are much less likely to cheat than when they work alone ${ }^{6}$; and that this is mostly because the female gets punished by being chased around by the male if she slacks off?' 


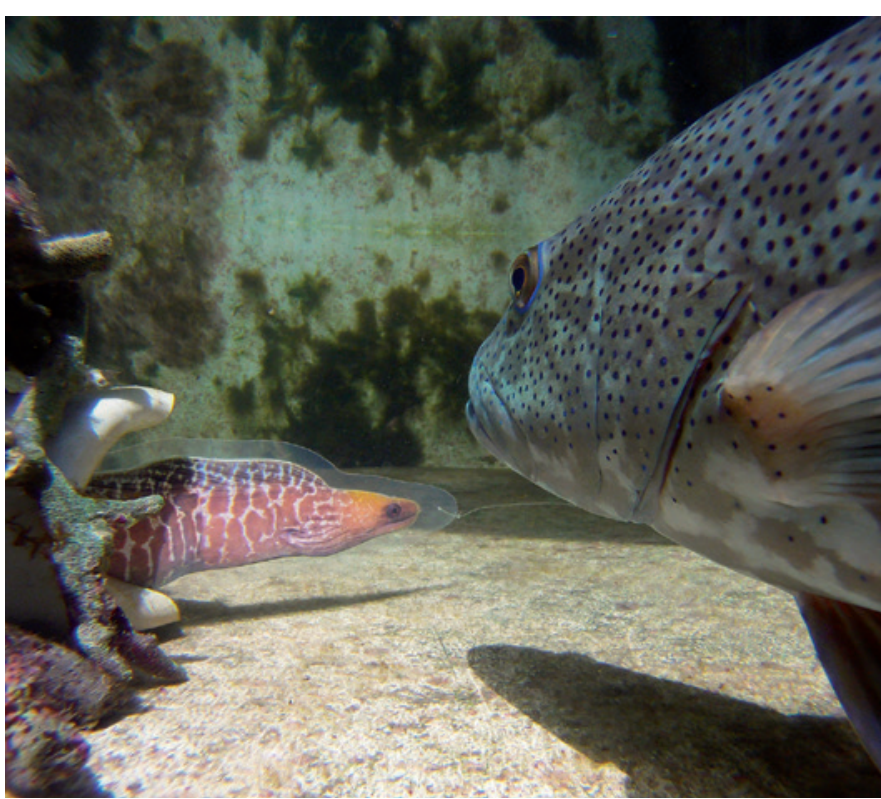

A fake moray, made from a laminated photo, fools a grouper fish.

Perhaps the laboratory's most imaginative experiment involved the construction of an entire fake coral reef, complete with dummy eels. The job fell to doctoral student Alex Vail, who glued together bits of coral rubble and put them in a hot-tub-sized tank. Vail then made models of moray eels by printing, gluing together and laminating two life-sized photographs, and attaching nylon strings that allowed him to pull the fake eels out of the fake coral, like a puppet. (Vail subsequently went on to a successful career in underwater filming.) Using this set-up, the team explored the behaviour that so shocked Bshary when he observed it in 1998: a grouper and eel teaming up to flush out fish to eat. They showed that the grouper quickly learnt to signal — by turning and shaking its head - only to those moray eels that responded by moving towards, rather than away from, the fake reef.

Bshary amassed ample evidence that fish engage in a range of social behaviours, and he assumed that all of them resulted from simple evolution at work. Natural selection favoured fish that could learn, by simple association, which choices allowed them to efficiently rid themselves of parasites or access food.

By 2010, Bshary's thoughts were turning back to the world of primatology, in which he had been immersed during his $\mathrm{PhD}$. He knew that he had observed in fish many of the behaviours that primatologists had shown in monkeys and apes. But primatologists had made grander claims for their observations. The 'social brain' theory argues that primates evolved brains that are large for their body size to manage their unusually complex social systems. Only primate brains, the theory says, have the depth of cognitive analysis necessary to cooperate, deceive and solve other problems in a social world.

Bshary disagreed. Maybe, he thought, these particular social behaviours in primates were also learnt by simple association and did not require the extra computing power of their big brains. And his findings meshed with those emerging from studies on the social behaviours of other animals, ranging from elephants to birds. "I think primatologists tend to make big claims because they look up the evolutionary chain and compare the primates' behaviours to humans, instead of looking down the evolutionary chain to see if the phenomena also existed in lower species," he says.

At the time, primatologists were certainly not looking at fish. But that changed when Bshary teamed up with primatologist Sarah Brosnan at Georgia State University in Atlanta to directly pit the skills of cleaner fish against capuchin monkeys, chimpanzees and orang-utans in a foraging test. Each animal was presented with food on two differently coloured plates, one of which was a permanent fixture in their tanks or pens, whereas the other was temporary. The challenge was to learn to eat from the temporary plate first, before it disappeared — and the scientists counted how many trials it took for the animal to figure this out.

The cleaner fish solved the problem first ${ }^{8}$; they have evolved in their ecological niche to preferentially feast from visiting clients before they disappear. For fun, Bshary set up an equivalent 'foraging' test for his four-year-old daughter, complete with temporary and permanent plates, each bearing one chocolate M\&M. In a series of 100 different trials, she never learnt to eat from the temporary plate.

The fish, meanwhile, were already aceing a more advanced test. When Bshary and Brosnan switched the coloured plates so that the permanent one suddenly became temporary and vice versa, the fish again understood the switch faster than the apes did (and equally as fast as the capuchins) ${ }^{8}$. This is known as reversal learning - and when the primatologists read that result, they took note. "Reversal learning has often been touted as the gold standard of general cognitive abilities," says van Schaik - a sophisticated skill that correlates with brain size. "Since small-brained fish do it quite well, maybe we'll have to abandon this idea."

"The ball is in our court," says evolutionary psychologist Robin Dunbar of the University of Oxford, UK, who developed the social brain theory. Dunbar now accepts that the evolution of large brains was not driven by the need to carry out single 'smart' behaviours such as cooperation or deception. But that doesn't mean the social brain theory has to be abandoned, he says - just refined. He and other primatologists now propose that primates evolved bigger brains because they needed an all-round high level of general intelligence to survive the pressures of living in tight social groups - for example, to recognize large numbers of individuals and remember their complicated genetic and hierarchical relationships.

Fish, which tend to have one-on-one interactions and live in loose schools, do not need to multi-task in quite the same way, Dunbar says. "It may boil down to the speed of cognitive processing and accuracy of judgement," he suggests.

\section{Intelligence tests}

Michael Tomasello, an evolutionary psychologist at the Max Planck Institute for Evolutionary Anthropology in Leipzig, Germany, bounces the ball right back to Bshary, challenging him to show how smart fish really are. "Perhaps the most pressing question is how flexible and general fish cognition is," he says - something Bshary is already testing by designing further fish intelligence tests.

The mysteries of the fish brain deepened in 2009, when Bshary's team chanced across a habitat in the reefs around Lizard Island that had relatively few fish and therefore less competition and social complexity. To Bshary's surprise, the cleaner fish there turned out to be much less socially smart than cleaner fish just 20 metres away ${ }^{9}$. But their skill level may be optimal for their environment - another hypothesis that he now plans to explore.

Whatever the next instalment brings, colleagues say that Bshary has already shifted a view of animal cognition in which humans and their primate cousins tower over everything else. "Primate chauvinism may now be poised to decline, thanks in large part to Bshary's fish work," says primatologist and ethologist Frans de Waal of Emory University in Atlanta, Georgia. "They now really do have to take on board that most species are going to have a type of smart intelligence."

Alison Abbott is Nature's senior European correspondent.

1. Noë, R. \& Hammerstein, P. Trends Ecol. Evol. 10, 336-339 (1995).

2. Bshary, R. \& D'Souza, A. in Animal Communication Networks (ed. McGregor, P. K.) 521-539 (Cambridge Univ. Press, 2005).

3. Bshary, R. \& Grutter, A. S. Biol. Lett. 1, 396-399 (2005).

4. Bshary, R. \& Grutter, A. S. Nature 441, 975-978 (2006).

5. Bshary, R. \& Würth, M. Proc. R. Soc. Lond. B 268, 1495-1501 (2001).

6. Bshary, R., Grutter, A. S., Willener, A. S. T. \& Leimar, O. Nature 455, 964-966 (2008).

7. Raihani, N. J., Pinto, A. I., Grutter, A. S., Wismer, S. \& Bshary, R. Proc. R. Soc. Lond. B 279, 365-370 (2012).

8. Salwiczek, L. H. et al. PLoS ONE 7, e49068 (2012).

9. Wismer, S., Pinto, A. I., Vail, A. L., Grutter, A. S. \& Bshary, R. Ethology 120, 519-531 (2014). 